International Journal of Database Management Systems ( IJDMS ) Vol.4, No.5, October 2012

\title{
Three Tier level Data Warehouse Architecture for Ghanaian Petroleum Industry
}

\author{
JerryYao Deku ${ }^{1}$, Mohammad Sarrab ${ }^{2}$ and Hamza Aldabbas ${ }^{1}$ \\ ${ }^{1}$ Faculty of Technology, De Montfort University, Leicester, United Kingdom \\ \{jesgeog200@yahoo.co.uk, hamza@dmu.ac.uk\} \\ ${ }^{2}$ Communication \& Information Research Center, Sultan Qaboos University, Oman \\ sarrabesqu.edu.om
}

\begin{abstract}
The data warehouse $(D W)$ is a modern proven technique of handling and managing diversity in data sources, format and structure. Recent advances in database technologies are leading to the proliferation of different kinds of information design with independent supporting hardware and software. This technology was developed therefore to integrate heterogeneous information sources for analysis purposes. Information sources are progressively becoming autonomous and they change their content rapidly due to perpetual transactions (data changes) and may change their structure due to continual users' requirements evolving (schema changes). Handling correctly all type of these changes however is a real challenge. Thus, strategic decision making is an ongoing process and part of human life. Businesses all over the world are faced with challenging decision making which is the very livelihood to their very existence. There has been intensive research in the field of databases including the grandfather of data warehousing Inmon which they offered tremendous insight into how the power of computing can be harnessed in strategic decision making. There achievement in the petroleum industry has been highlighted and written about by Nimmagadda and his fellow professionals. However how this can be implemented in Africa is remain to be solved. In this paper we investigated the various data capturing systems which they currently in use at the Ghana National Petroleum Cooperation (GNPC) - a state agency responsible for the overall management and supervision of the hydrocarbon endowment of the sub-region and recommending a tree tier level petroleum data warehouse architecture for cutting- edge decision making on petroleum resources.
\end{abstract}

\section{KEYWORDS}

GNPC, Petroleum data warehousing, Data warehouse architecture, Ghanaian petroleum industry.

\section{INTRODUCTION}

Ghana came into the spotlight in 2007 for its first ever discovery of hydrocarbon in commercial quantities. According to reports, the country is set to produce 1.4million gallons of crude oil per year, shooting the country's wealth up by a warping 4 billion dollars a year. Economic growth is also estimated to increase more than $13 \%$ per annum [1]. All these economic developments in the country raised the issue of how all these plans have been made without using a reliable data. As a matter of fact that for any country to achieve international reputation should depends greatly on the pro-activeness of its government and its citizens, especially the research reports to be able to anticipate the ramifications of their decisions and to put in place appropriate contingency plans to mitigate them. However this cannot be done without using the right information carefully 
International Journal of Database Management Systems ( IJDMS ) Vol.4, No.5, October 2012

formatted, faultlessly triangulated, craftily and rightly positioned at the right place relative to each other for cutting edge decision making. Quality data and vibrant is the key to success of this fast growing industry. The importance of data is once again captured by the fact that the organisation makes approximately about US\$2 million from data licensing per annum and presently provisions are being made to embark on a US\$10 million project that would see to the establishment of an online four levels architectures data store (the so termed data farm) supported by a meta data for faster and easier access to information. In this paper we looked at how data warehousing can be integrated into this data farm for efficient and effective extraction of necessary data for tactical decision making.

This paper presents a new data warehouse framework for the Ghanaian petroleum industry, Ghana is a relatively small but powerful country in sub-Saharan Africa - the republic of Ghana which recently idiomatically struck gold fortunes on its sea beds in the form of hydrocarbon deposits. In this context, some of the key questions that can be asked; what are the government's plan for continual discovery, exploration and preservation of this resource for the citizens of Ghana, and if there are any, are these plans made based on readily available, factual and highly summarised data or they are the decisions of the pre-computer age. Data warehouses are said to provide artificial support for management decision making but can this be of any use to the Ghanaian petroleum exploration industry. This paper seeks to provide answers to these questions by investigating the various data capturing systems currently in use at the Ghana National Petroleum Cooperation - a state agency responsible for the overall management and supervision of the hydrocarbon endowment of the sub-region and recommending petroleum data warehouse for cutting- edge decision making on petroleum by government. Interviews supported by some level of participant observation methods are adopted for gathering information in this paper. Transcription was the main analysis tool utilised in identifying themes, trends and building interpretations around them.

\section{RELATED WORKS}

The term data warehouse just like any other term in the professional domain has received many scholarly attentions over the years with criticisms and counter criticisms by many database technologists. However, Inmon in 1993 has it that "a data warehouse is a subject oriented, integrated, time variant and non-volatile collection of data in support of management's decision making" [2]. This is not a one stop definition since many scholars have varying views about what should be the embodiment of the definition for the term and what should not. However from the above definition of a data warehouse it is lucently clear that the definition of the term data warehouse should rest on four main building blocks which I would comfortably want to refer to as the four "defi-pillars" of data warehousing - that is its non-volatility, subject-orientation, integrated and it's time-variant.

The concept of petroleum data warehousing has been written about by many professionals. The following are some of the academic works done in the domain and for an exhaustive digestion of the topic, it is recommended that this paper be read in conjunction with some of these academic papers as listed below,

- Mapping and modelling of oil and gas relational data objects for warehouse development and efficient data mining \& On issues of data warehouse architectures - managing Australian resources data [3].

- Building the data warehouse [2]. 
International Journal of Database Management Systems ( IJDMS ) Vol.4, No.5, October 2012

- Research on the application of data-mining for quality analysis in petroleum refining industry [4].

- The application of spatial data warehouse technology in the national petroleum resources database [5].

Data warehousing involves the polling together of data from various data islands and operational data bases and storing it in a persistent, integrated, subject specific and time variant format for an informed strategic management decision making [2].On the business front, It is always promoted by developers and other major stakeholders as having the capability to revolutionise businesses by transforming management decision making process in terms of its speed, precision, reliability and real-timeliness.

However, in recent years, the concept has become a hot topic in mining and mineral resources business computing and it is often used to capture, store and access resources and their latent dimensions of strategic information encapsulated by different operational data. Such data includes super type entities such as exploration data, production data, drilling data, and marketing data each of which has branches called subtypes [6]. This task is virtually unachievable by relational database management system built for online transaction processing due to its rigidity and inability to offer the required multiple dimensions that would intend bring out aspects for OLAP analysis [7]. In an investigative approach to model the Australian resource data, Nimmagadda and Dreher $[3,6]$ provided a mapping and modelling technique for extracting and preparing data and offered an exhaustive methodology on how this is then integrated into a framework to form the Australian petroleum resource data warehouse. In a related work by Ying, Yang, Ya-fu and Lixhou [5], generic data warehouse approaches were utilised to achieve a spatial data warehouse design by systematically illustrating how the various enterprise-wide data is coordinated into a single repository and multi- dimensionally modelled into a high level decision making a tool. However despite the enormity of research work in the subject domain, many of these works have not been able to provide a logical approach and methodology on how the data warehouse can be integrated into the global information system for rapid, economical and cost saving development while ensuring that the existing information flow channel is not compromised. In this paper we provide an approach to achieve this by introducing the three tier level data warehouse architecture in the Ghanaian petroleum exploration information management system.

\section{THE DATA WAREHOUSE DESIGN}

Data warehouse design is usually captured using the star schema methodology. As the name suggests, there are many ends to a star hence unlike the traditional relational database which has only two ways of representing data, that is in rows and columns, a data warehouse uses a technology called the multi-dimensional database design with multiple ends dimensions which grows bigger as more data is added to the warehouse.

A typical star schema would have just only one fact table in the middle surrounded as many dimensions as required which allows for different perspectives of the data to be formed. A star schema can be simple or complex. A simple star consists of one fact table; a complex star can have more than one fact table. In the case of the petroleum industry, the fact table could be a well fact or production fact. 
International Journal of Database Management Systems ( IJDMS ) Vol.4, No.5, October 2012

A star schema gradually gives way to snowflake schema where each point of the star explodes into more points. In a star schema, each dimension is represented by a single dimensional table, whereas in a snowflake schema, that dimensional table is normalized into multiple lookup tables, each representing a level in the dimensional hierarchy. Figure 1 gives a diagrammatical depiction of the above phenomenon.

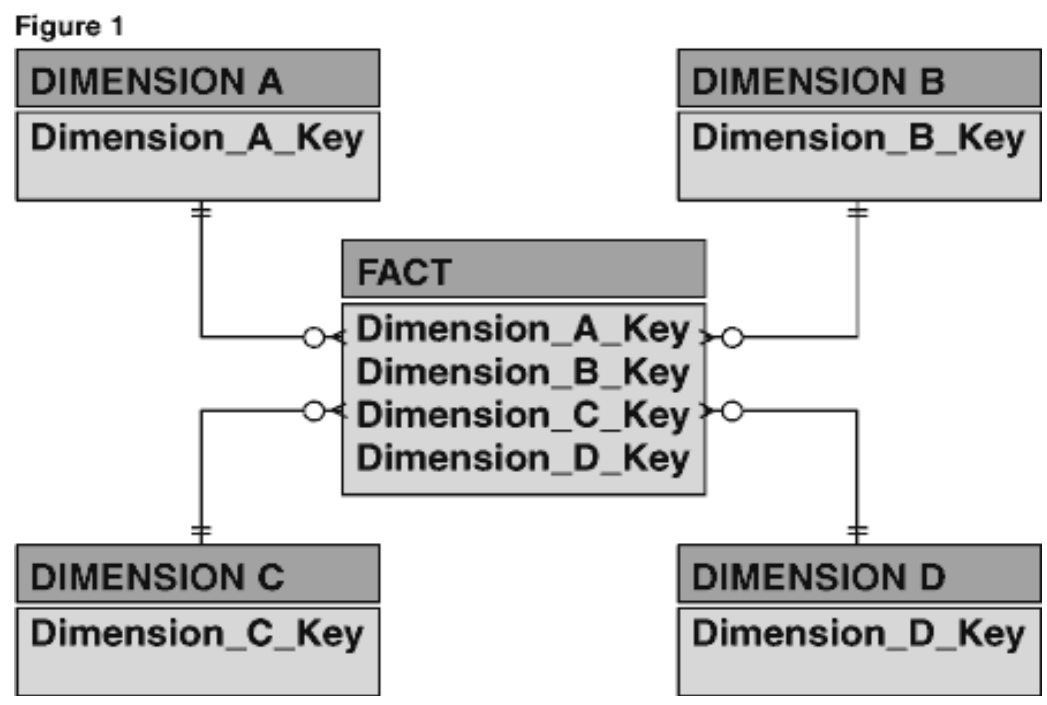

Figure. 1 A typical multi-dimensional database

However, this is not enough to depict the time variance and geographical aspect of the data. In effect therefore to better capture these dimensions snowflake schemas are used in which composite dimensions such as the period of drilling which for example can be divided into variant time units such as days, weeks, months and years each of which springing out from the period dimension. The analyst then investigates the patterns of data according to day, week, month, quarter and year. In such a case, during the mapping process, dimension relations have to be normalized. Redundancy of dimension tables also needs to be addressed to reduce the complexity of data slicing. In these situation issues of normalisation in case of many-to-many multiplicities are usually resolved using relationships. The schema that is derived with such a process is called a snowflake. As more data and dimension is added to the flakes it grows bigger and bigger resulting in numerous branches of cubes at each end of the dimension of the flake. The drilling flakes are carefully extracted and position in clusters to form the data warehouse.

\section{The Ghanaian Petroleum Data Management System}

The Data Management Centre of the Department (GNPC) is a modern 9100sq. ft. building complex, containing laboratories and office space, and data storage facilities (approximately 4000 sq. ft) for the storage of hydrocarbon data. The centre is located on the Accra-Tema bypass road (Spintex Road), approximately 5 miles east of the airport in Accra separated from the main office located in the industrial city of Ghana -Tema. The mission of the unit is to provide a secure and managed storage environment for Ghana's heritage of geological and geophysical data. These data have been obtained over a period of many years during the search for hydrocarbon resources. The data types include technical data and reports, rock cores and geological samples, seismic sections, and digital tapes. The Centre has developed a catalogue of all exploration and 
International Journal of Database Management Systems ( IJDMS ) Vol.4, No.5, October 2012

production data and related information. The catalogue is computer-based, to provide the exploration with complete and comprehensive listing of all available material and information to assist in the on-going search for hydrocarbon resources. Each catalogued item is assigned a unique code and storage location, and catalogues are managed by a computerized data management system. It is envisaged to provide on-line global data access and geological services. It must be noted that the existence of a computerised data gives a positive indication for a possible warehouse to be constructed. Also the reference to unique keys (primary keys) allocated to each data entity further gives the process additional boost. These keys usually serve as indexes to the data cubes and are positioned in the fact table to facilitate easy retrieval of data.

\section{DATA TYPES}

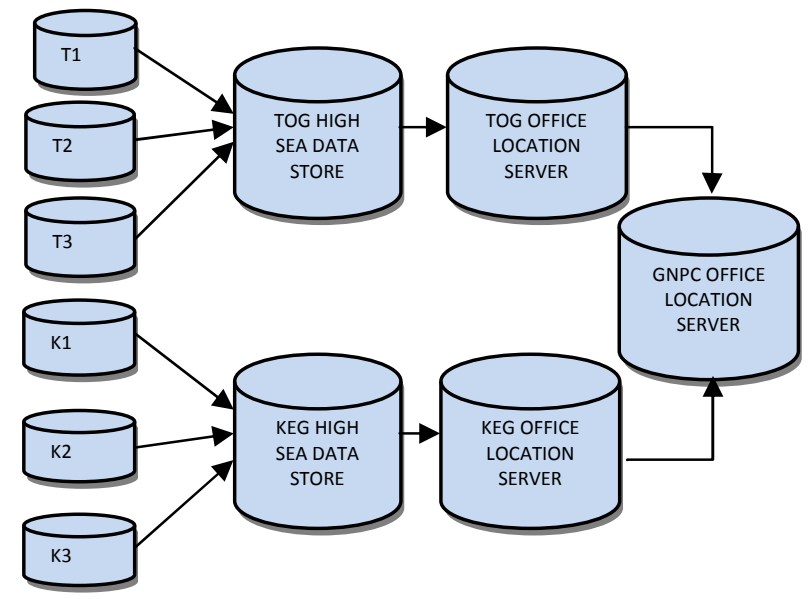

Figure 2. Conceptualized model of dataflow between GNPC and its partners.

Data stored is catalogued under the following major categories: Archival includes any corporate information that GNPC have deemed to be inactive, but necessary to keep in an organized manner for possible future reference. Displays include well information, cores, samples, reports, logs and surface samples.

Geophysical includes seismic and gravity/magnetic line detail, reports, sections, and digital tapes. Library includes books, magazines, and technical reports

\section{METHODOLOGY}

Since the research followed the consultancy path which was aimed at producing a consultancy form of report with recommendations to the client organisation, we emphasized that it was not meant to find out how many people does A or B or how many more women in the organisation carry out an activity or set of activities than men. Quantitative research which usually embraces the positivist ideology follows the scientific investigation path and objectively investigates issues and deals normally with statistical data. The objective of this research therefore differs from the positivist ideology of tabulating figures and establishing the relationship between them. This 
International Journal of Database Management Systems ( IJDMS ) Vol.4, No.5, October 2012

research therefore embraced the interpretive ideology and trailed on the path of the qualitative research. In addition, the idea of the iterative research ovule (following the path of the iterative systems lifecycle) was introduced to depict the flexibility that must employed in investigating IT issues as illustrated in the diagram below.

In support of the above, Wisker in 2001 hammered that researchers employing interviews under qualitative research have the competitive advantage of unintentionally forcing much details from their respondents by giving them the free will to express their deeper feeling about the concept while the researcher on the other hand is given the opportunity to explore the idea behind their way of thinking unlike the restrictive quantitative approach [8].

To this end, the investigation employed both observation and interviews while relying on some amount of secondary data for critical analysis of existing trends and methodologies. Weaver in 2004 established that the use of interviews in probing and demystifying computing issues helps build a long lasting bond between the interviewer (the project team) and the interviewee [9].

\subsection{THE SURVEY}

Two main companies in the oil industry in Ghana - the Ghana National Petroleum Corporation (GNPC) and Tullow Oil Ghana (TOG) were interviewed to gather mainly qualitative data to enable the researcher to develop a conceptual view into their activities (background information) and their data storage workflow and requirements [10]. In addition to this, secondary data on one company- the Kosmos Energy Ghana limited (KEG) was also obtained in other to have a more complete picture of the investigation [11]. Among the people interviewed are the information systems managers, administrators, members of management decision making body and some selected non-managerial staff to help in obtaining details about operational data held by the department?

Transcription was the analysis tool employed to reveal the core meaning in the array of obtained set of responses. However this is not enough to bring out trends and aspect of the data. To do this, the power of thematic analysis was employed to segregate the data and bring out aspects which then helped shaped the development of the architecture and as well guided the recommendations suggested to management.

The researcher prior to the start of the investigation planned to interview as many as five companies involved in the oil exploration activity in Ghana. However at the preliminary stage of the actual fieldwork, it came to light that many of the companies including the Saltpond offshore production company limited (SOPCL), Sabre oil, Anardako Ghana limited and the E.O group Ghana Limited have not started any serious exploratory work in their respective fields.

This is attributed to the infant nature of the industry and hence goes a long way to buttress the researcher's ambitiousness and pro-activeness to research into the area. The only alternative the situation presented to the researcher is to focus on the two fields currently under exploration. In this direction therefore, the researcher was strained to rely on data obtained from interviewing the active companies notably the Tullow Oil Ghana Limited (TOG) and the Ghana National Petroleum Corporation (GNPC) while relying on secondary data obtained on Kosmos Energy Ghana Limited (KEG) to build a more complete picture of layout $[10,11]$. 
International Journal of Database Management Systems ( IJDMS ) Vol.4, No.5, October 2012

However upon several participant observations with these two companies and as contained in the responses to the interviews, it came out that there is indeed a logical layout of flow of information between these three companies thus fulfilling the requirement of the research. Consequently, the government of Ghana as stipulated by the legal provisions requires that all data relating to Ghanaian petroleum industry generated by the various stakeholders in the industry be made available to the GNPC who then persistently house these data for the consumption of the general public, the government, and other state holders both abroad and localised thus serving as a candidate for possible implementation of data warehouse. The GNPC works closely with its partners namely the KEG and TOG which in conjunction with the other dormant companies categorised above serve as the primary generators or sources of these data.

\section{RECOMMENDATIONS TO THE CORPORATION}

The benefits presented by data warehousing in businesses and more especially petroleum domain are wide and unlimited. Kimball et al in 2008 wrote that these benefits can be demarcated into two main categories - the tangible and the intangible [12].

The tangible benefits they said ranges from:

- Increment in business turnover

- Elimination of the cost of producing legacy reports

- Reduction in time in pulling together data for analysis.

While the intangible among other things embrace those benefits that direct value cannot be put on and includes the following:

- Timely and easy access to managerial decision data

- The discovery of relationships or knowledge that would have been embedded in data without being noticed through data mining technologies.

- Reduction in work burden on employee

- Precise rapid and cutting edge decision making.

Based on these numerous benefits and by the proclamation of the corporation that some managerial decisions are currently and constantly being withheld or hindered due to the sheer fact that data is currently available but does not exist as a common pool to facilitate rapid decision making, the researcher having thoroughly analysed the data and with personal communications held with management during his observation session recommends that a data warehouse could be the most probable solution to this problem. The data islands in this situation are notably Tullow oil Ghana (TOG) and Kosmos Energy Ghana (KEG) the operators of the Jubilee fields who form the prime focus of this research and the other operators both in the process of securing a licence and those already with licence but currently doing the ground work for official exploratory work to begin $[10,12]$.

Apart from TOG and TEG the cooperation also houses various databases both in its head office location in the industrial city Tema and the data management unit off the Spintex road in Accra. As indicated by the department data in the data management unit are catalogued under various categories. The research thus established that all these entries be scanned if possible or captured and integrated into their respective operational databases (first level data store).This is necessary 
International Journal of Database Management Systems ( IJDMS ) Vol.4, No.5, October 2012

to allow for easy and rapid upload into the oracle data store (second level data store). We have for some time now been considering the establishment of a common repository of data (data farm) supported by online tools for accessing the data and currently the necessary proposals are being approved for the establishment of one, a manager proclaimed. Under this same project a super server is to be purchased and this would form the backbone for pulling together blocks of data from the various islands or silos including those currently being held by TOG and TEG due to unavailability of adequate storage facility at GNPC. However as a common practice in data warehousing, this online data farm cannot be deemed to provide answers to management questions due to the fact data warehouses and Online Transaction Processing (OLTP) systems have very different requirements.

It is therefore recommended that double server architecture be formed rather than the single server architecture. The super server as it was proposed would still go ahead to pool together heterogeneous operational data from the various data islands into a single homogenous repository of data farm and would serve as the main feeder of data to the data warehouse.

In effect a three level architecture has been recommended to the department and this would be discussed by the sub-chapter below.

\section{BuILding The CONCEPTUAL ARCHitecture MODEL}

Just like any software development project, data warehouse also follow a set of milestones to ensure that a working system is delivered on time and to ensure that all user requirements has been fully captured by the design.

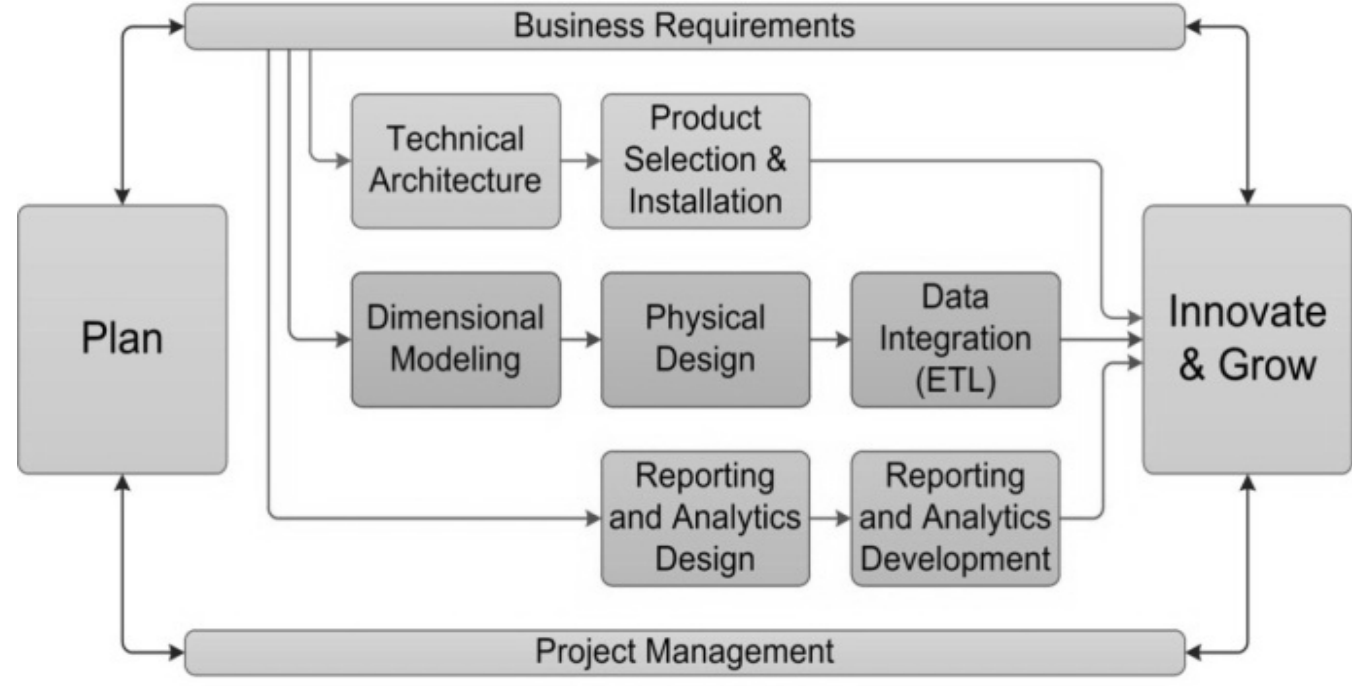

Planning \& Architecture $\square$ Data Modeling \& Integration $\square$ Reporting \& Analytics

Figure 3. The Kimball data warehouse development lifecycle.

Source: www.teknionusa.com (2011) [13]

The successful completion of the activities within a systems lifecycle reassures the project team that the information system developed is in line with organisational needs [1]. Thus the architecture shall employ the Kimball's lifecycle methodology. Kimball in 2008 outlined that for a data warehouse project to be successful does not really depend on the quantity and quality of data or the best combination of sophisticated modern technologies but rather how the task and 
International Journal of Database Management Systems ( IJDMS ) Vol.4, No.5, October 2012

components in the development project are blended and coordinated for the best delivery of product [11]. Thus the lifecycle ensures that the project constituents are positioned at the right place within the project and that this is done at the right time. The diagram below is a depiction of the proposed project lifecycle by Kimball. However, a lifecycle cannot operate in a vacuum. It must have an approach or methodology within which it operates or shape thus the approach recommended to management is the top-down approach as outlined by Paulraj Ponniah. "The topdown approach is to start at the enterprise-wide data warehouse, although possibly build it iteratively and then data from the overall enterprise-wide data warehouse flow into departmental and subject data marts" [14].

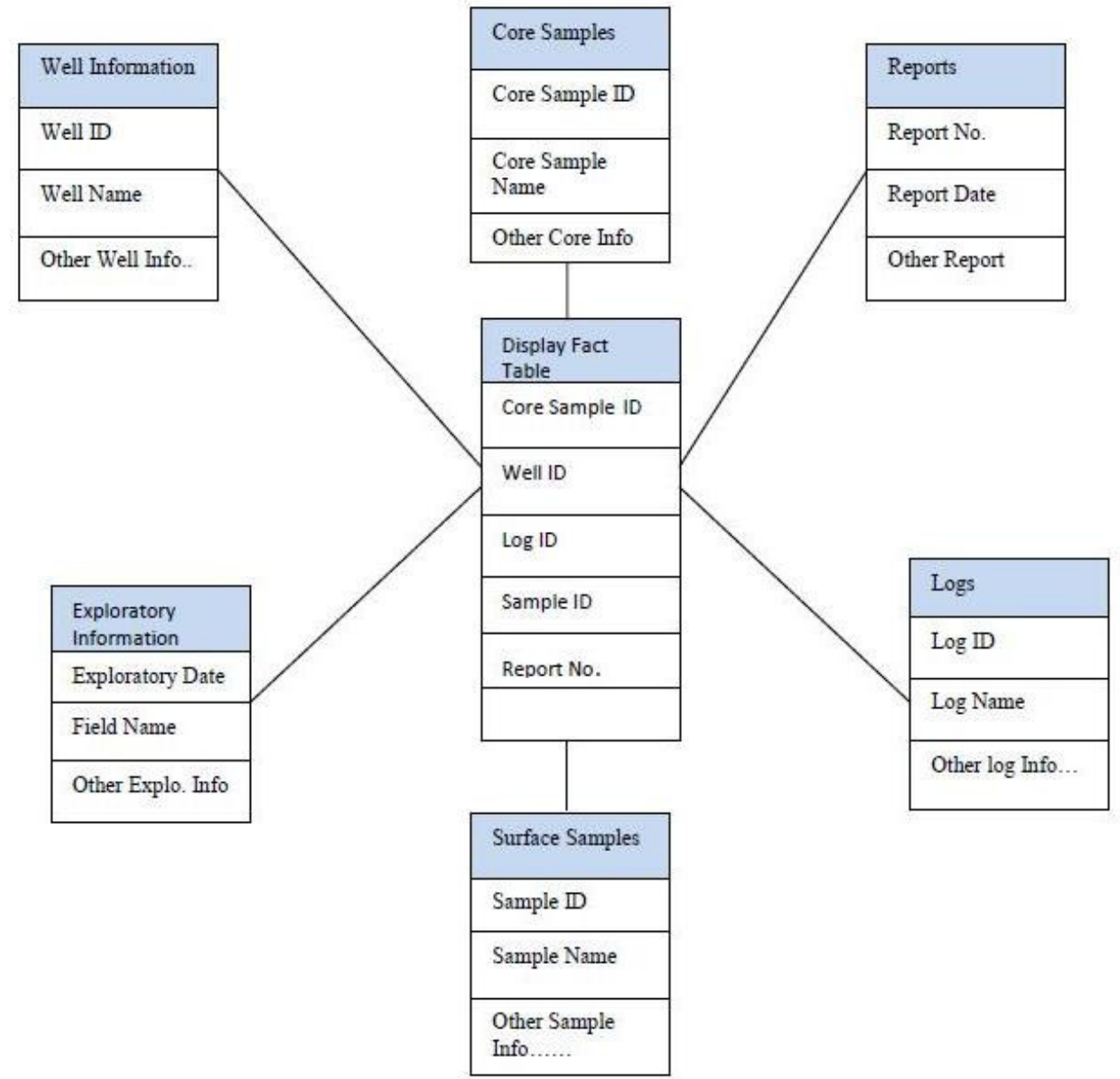

Figure 4. A multi-dimensional model of the display category

This approach is a strategic step following the nature and layout of the architecture. From the architecture, the corporation has the vision of integrating data from the various operational databases into one big store house (the super server). From here it would be a waste of time and resources to re- disintegrate the data into data marts before re-integrating into the enterprise-wide data warehouse. Thus a more economical way to do this is to follow the top- down approach for a faster and timely delivery.

Model of the schema: For the purpose of the schema, the multidimensional database design shall be the main focus to help us capture the various dimensions accurately. However emphasis 
International Journal of Database Management Systems ( IJDMS ) Vol.4, No.5, October 2012

is placed on st a portion of the holding that are involved in active decision making by the department notably those that fall under the display and the geophysical data. The various dimensions are captured diagrammatical by the schema below:

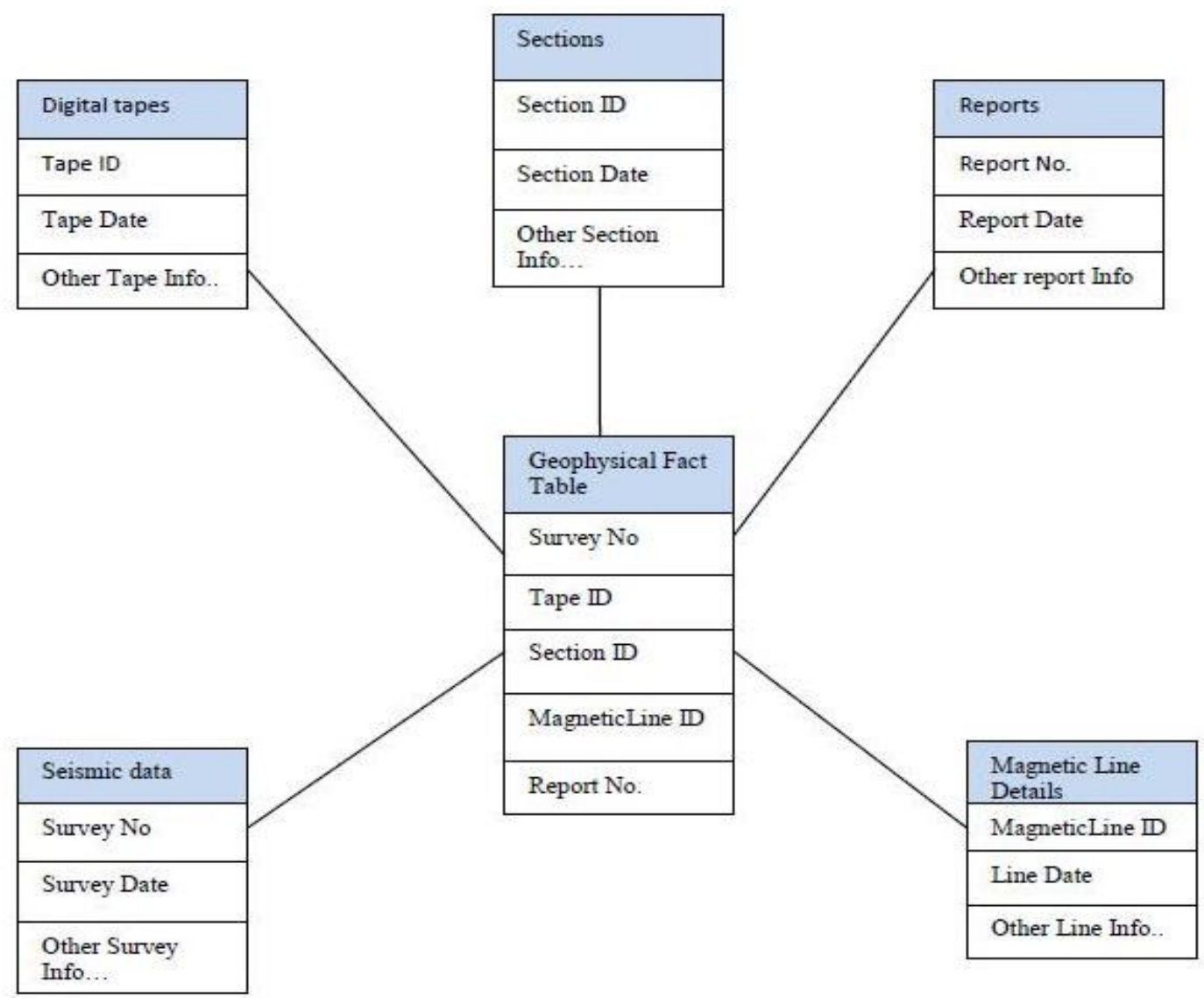

Figure 5. A multi-dimensional model of the geophysical category -

Data warehouse architecture is a way of representing the overall structure of data, communication, processing and presentation that exists for end-user computing within the enterprise [6] thus the model in Figure 6 below represent the three tier level data warehouse architecture recommended to the department. 


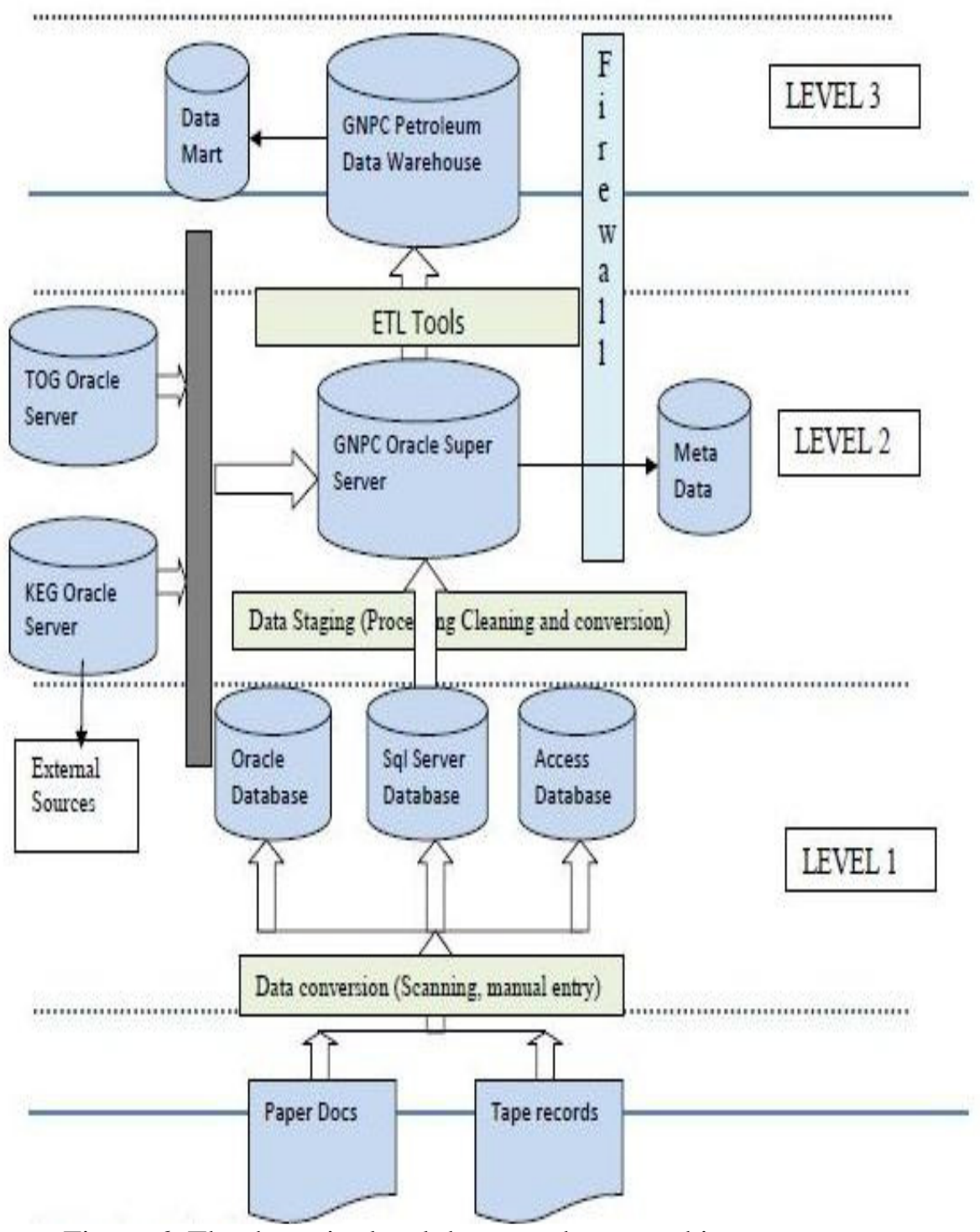

Figure 6. The three tier level data warehouse architecture

\section{CONCLUSION}

This paper has accomplished the mission of constructing a data warehouse model for the Ghanaian petroleum industry. In all three companies has been investigated in the petroleum exploratory sector and in effect it was revealed that a producer-ownership relationship in terms of data exist between these three companies. However GNPC as the custodians of the information lacks the appropriate facilities to well house and manage these data and in effect has been facing constant managerial decision making due to information dispersion across the organisation and its partners. This leads to the formulation of various goals and objectives and in effect a number of investigative approaches, methodologies and strategies have been brought together resulting in 
International Journal of Database Management Systems ( IJDMS ) Vol.4, No.5, October 2012

the construction of the model in Figure 6. This if implemented is believed to eliminate the current obscurities encountered in managerial cum government decision making on petroleum resources.

\section{FUTURE WORKS}

The oil and gas exploratory business unlike other merchant businesses make use of variety of heterogeneous data existing in different formats ranging from maps (JPEGs) to reports and figures. Even though data warehousing can help extract meaningful and factual information, the heterogeneous nature of the data still place a great amount of limitation on the quality thus presenting A unique and viable research area on the possible ways by which these heterogeneous data can be homogenised and converted into one compatible format before loading into the warehouse for the for optimization and better productivity of the data warehouse. One great limitation of this research is the non-availability of data due to the young nature of the industry thus the research is limited to the Jubilee fields and its operators.

However we cannot confidently extend the findings of this research to the other companies in the process of commencing exploratory work in their respective fields due to issues of underlying geological rock differences and the contents of such fields (that is gas or oil or both). In effect an extensive work would have to be initiated on these individual fields to determine how best they can fit into the entire architecture.

\section{REFERENCES}

[1] BENNET, S., MCROBB, S. \& FARMER, R. (2010), Object-oriented systems analysis and design using UML, 4th ed. London: McGraw-Hill.

[2] INMON, W.H. (2005), Building the data warehouse, 4th ed. Indiana: Wiley Publications Inc.

[3] NIMMAGADDA, S.L \& DREHER, H. (2009), Mapping and Modelling of Oil and Gas Relational Data Objects for Warehouse Development and Efficient Data Mining, Institute of Electrical and Electronic Engineers, (August), pp.1201-1205.

[4] CHEN, J.et al. (2004), Research On the Application of Data-mining For Quality Analysis In Petroleum Refining Industry, Institute of Electrical and Electronic Engineers, (June), pp.4214-4318.

[5] WANG, Y. et al (2010), The Application of Spatial Data Warehouse Technology in The National Petroleum Resources Database, Institute of Electrical and Electronic Engineers, (July), pp. 257-260

[6] MOHANTY, S. (2006), Data warehousing design, development and best practice, New Delhi: Tata McGraw-Hill.

[7] CONNOLLY T. \& BEGG, C. (2010), Database systems: a practical approach to design, implementation and management, 5th ed. London: Pearson.

[8] WISKER, G. 2001. The postgraduate research handbook. New York: Palgrave.

[9] MUCI-KUCHLER, K., AND WEAVER, J. 2004. Learning how to identify customer requirements: a key component of product development courses. In: Proceedings of the 2004 American Society for Engineering Education Annual Conference \& Exposition. Salt Lake City, UT: American Society for Engineering Education. 
International Journal of Database Management Systems ( IJDMS ) Vol.4, No.5, October 2012

[10] TULLOW OIL GHANA. (n.d), About Tullow Ghana, [WWW]. Tullow oil Ghana. Available from: http://www.tullowoil.com/ghana/index.asp?pageid=61 [Accessed 04/08/11].

[11] KIMBALL, R. et al. (2008), The data warehouse lifecycle toolkit, Indiana: Wiley publishing inc.

[12] KOSMOS ENERGY GHANA. (n.d), Kosmos Energy Genesis, [WWW]. Kosmos energy Ghana. Available from: http://www.kosmosenergy.com/aboutus.html [Accessed 04/08/11].

[13] TEKNION (n.d), Business Intelligence, [WWW]. Teknion. Available from: http://www.teknionusa.com/Solutions/Business-Intelligence/Pages/BI-Methodology.aspx [Accessed 09/09/11].

[14] PONNIAH, P. (2001), Data warehousing fundamentals: a comprehensive guide for IT professionals, New York: John Wiley and Sons 